Article

\title{
Evolution Pattern and Matching Mode of Precursor Information about Water Inrush in a Karst Tunnel
}

\author{
Jie Song ${ }^{1,2}$, Diyang Chen ${ }^{3,4}$, Jing Wang ${ }^{2,3, *} \mathbb{B}$, Yufeng Bi ${ }^{1}$, Shang Liu ${ }^{1}$, Guoqiang Zhong ${ }^{1}$ and Chao Wang ${ }^{1}$ \\ 1 Shandong Provincial Transportation Planning and Design Institute, Jinan 250061, China; \\ tom1442@sina.com (J.S.); 18866130036@163.com (Y.B.); lssdu0408@163.com (S.L.); zhong_g_q@126.com (G.Z.); \\ ws8727200@163.com (C.W.) \\ 2 School of Transportation Engineering, Shandong University, Jinan 250101, China \\ 3 Geotechnical and Structural Engineering Research Center, Shandong University, Jinan 250061, China; \\ chen729911@sina.com \\ 4 Research Institute of New Material and Intelligent Equipment, Shandong University, Dezhou 251100, China \\ * Correspondence: wjingsdu@163.com
}

check for updates

Citation: Song, J.; Chen, D.; Wang, J.;

Bi, Y.; Liu, S.; Zhong, G.; Wang, C.

Evolution Pattern and Matching

Mode of Precursor Information about

Water Inrush in a Karst Tunnel. Water

2021, 13, 1579. https://doi.org/

10.3390/w13111579

Academic Editor: Juan José Durán

Received: 2 April 2021

Accepted: 24 May 2021

Published: 2 June 2021

Publisher's Note: MDPI stays neutral with regard to jurisdictional claims in published maps and institutional affiliations.

Copyright: (c) 2021 by the authors. Licensee MDPI, Basel, Switzerland. This article is an open access article distributed under the terms and conditions of the Creative Commons Attribution (CC BY) license (https:// creativecommons.org/licenses/by/ $4.0 /)$.

\begin{abstract}
The water inrush of the Shangjiawan karst tunnel is used to study the evolution pattern of precursor water inrush information in water-filled caves and to further reveal the matching mode of the information. The three-dimensional numerical method FLAC3D was used to simulate the evolution process of water inrush after damage to a water-blocking rock mass structure in a waterfilled cave and to obtain the evolution pattern of precursor water-inrush information caused by the damage. The results show that the multifield response to the characteristic precursor information of the water-inrush pattern after the fracture of the water-blocking rock mass follows the order of stress-field displacement-field seepage-field. Further, the matching pattern of the information shows that the stress field increased first and then decreased, the displacement field always increased, and the seepage field increased first and then decreased.
\end{abstract}

Keywords: karst cave; water inrush; normalization treatment; precursor information

\section{Introduction}

As the focus of infrastructure construction in China gradually shifts to the western mountainous areas with extremely complex geological environments, the challenges of tunnel construction are ever increasing. In addition, most of the tunnel projects that are under construction or are about to be built in the western mountainous areas are high-risk karst tunnels, which have the characteristics of large burial depths, long tunnel lines, strong karst development and high water pressures [1,2]. Sudden water inrush disasters have gradually become a bottleneck, restricting the scale and development of tunnel construction in China [3].

In recent years, many scholars have studied the influence of filling-type karst caves on the tunnel construction process. In the aspect of numerical simulation, scholars used the SPH method to develop a fluid-solid coupling program, and used the finite element method and discrete element method to systematically study the evolution law of water inrush and other disasters in Karst tunnels [4-8]. In engineering practice, based on a variety of karst tunnels at home and abroad, scholars carried out field tests and studied the disaster-causing mechanism and treatment technology of water inrush and other disasters in karst tunnels [9-12]. In terms of theoretical deduction and analysis, scientists used the non-linear evolution theory, thin plate theory and shear failure theory to analyze the water inrush and other disasters of karst tunnels in detail, and revealed the influence law of karst topography on the tunnel construction process [13-16]. 
Because the precursor information of water inrush in karst caves has not been thoroughly studied and its mechanisms and evolution patterns are unclear, it is impossible to monitor and provide early warnings about water inrush in karst caves. Therefore, it is of great significance to investigate the evolution pattern of the precursor information of water inrush in karst to enable such monitoring and warning.

Based on the water inrush case of the Shangjiawan Tunnel of the Baokang Yichang Expressway in Hubei Province, China, the calculation model of an exposed karst cave is established by using the finite element software ANSYS 16.0 (Ansys, Inc., Canonsburg, PA, USA). The karst cave is simplified as a sphere, and the model is imported into the finite difference software FLAC3D V3.0 (Itasca Consulting Group, Inc., Minneapolis, MN, USA) for simulation excavation and equilibrium solution. The evolution laws of displacement field, stress field and seepage field of the tunnel and surrounding rock before water inrush are analyzed comprehensively. Through the normalization of data, the catastrophe analysis of multiple points of information is carried out, and the matching mode of water inrush and precursory information of water resisting rock burst is proposed.

\section{Study on the Pattern of Precursor Information of Water Inrush in Karst Cave}

Water inrush in high-pressure water-filled karst caves poses great safety threats in tunnel construction. Therefore, research on the mechanism of water inrush in high-pressure water-filled karst caves has not only important theoretical value but also important engineering significance. Yang [17] relied on an "in-door simulation system for water inrush in karst caves" (Figure 1) to study the macroscopic pattern of water inrush in karst caves in front of tunnels, and divided the water inrush into three stages: water seepage, water inrush and inrush stoppage. The following experimental phenomena and results were discussed. Water pressure was loaded according to the water pressure loading scheme. When the water pressure reached $0.1 \mathrm{MPa}$, water seepage began to appear in the lower part of the water-blocking rock mass (below the dissolution cavity). As the water pressure continued to increase, the water seepage area expanded from the bottom to the top, eventually covering the entire surface of the water-blocking rock mass. When the water pressure reached $0.3 \mathrm{MPa}$, the water pump was controlled at the pressure-holding state; the water seepage in the area below the water-blocking rock mass increased abnormally, and strands of seepage water connected to form a local trend of water inrush. When the water pressure reached $0.34 \mathrm{MPa}$, the water seepage in the lower water seepage area increased significantly, and a clear boundary was formed between the lower water seepage area and the middle and upper water seepage areas. Subsequently, a microcrack appeared below the dissolution cavity, which extended to the edge of the model approximately $20^{\circ}$ to the lower right. Under the action of water pressure, the crack continued to expand and propagate to the upper left, but its speed of propagation was significantly lower than its speed of expansion. Cracks appeared in the water-blocking rock mass and continued to expand and propagate; the first water inrush occurred when the water-blocking rock mass peeled off, and then small pieces of rock fell to form mud inrush in the second stage. The whole process lasted for a very short period of time, which was less than $2 \mathrm{~s}$; the occurrence was transient, the water-blocking rock mass protruded as a whole, and the degree of damage was great. The process is shown in Figure 2. 


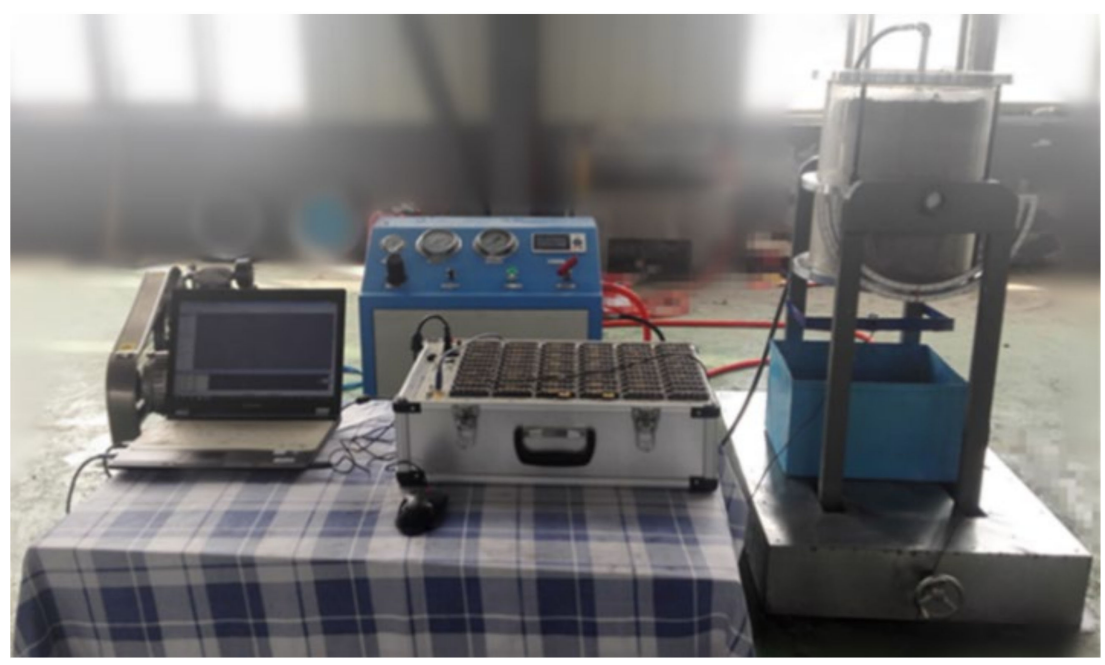

Figure 1. Test system.

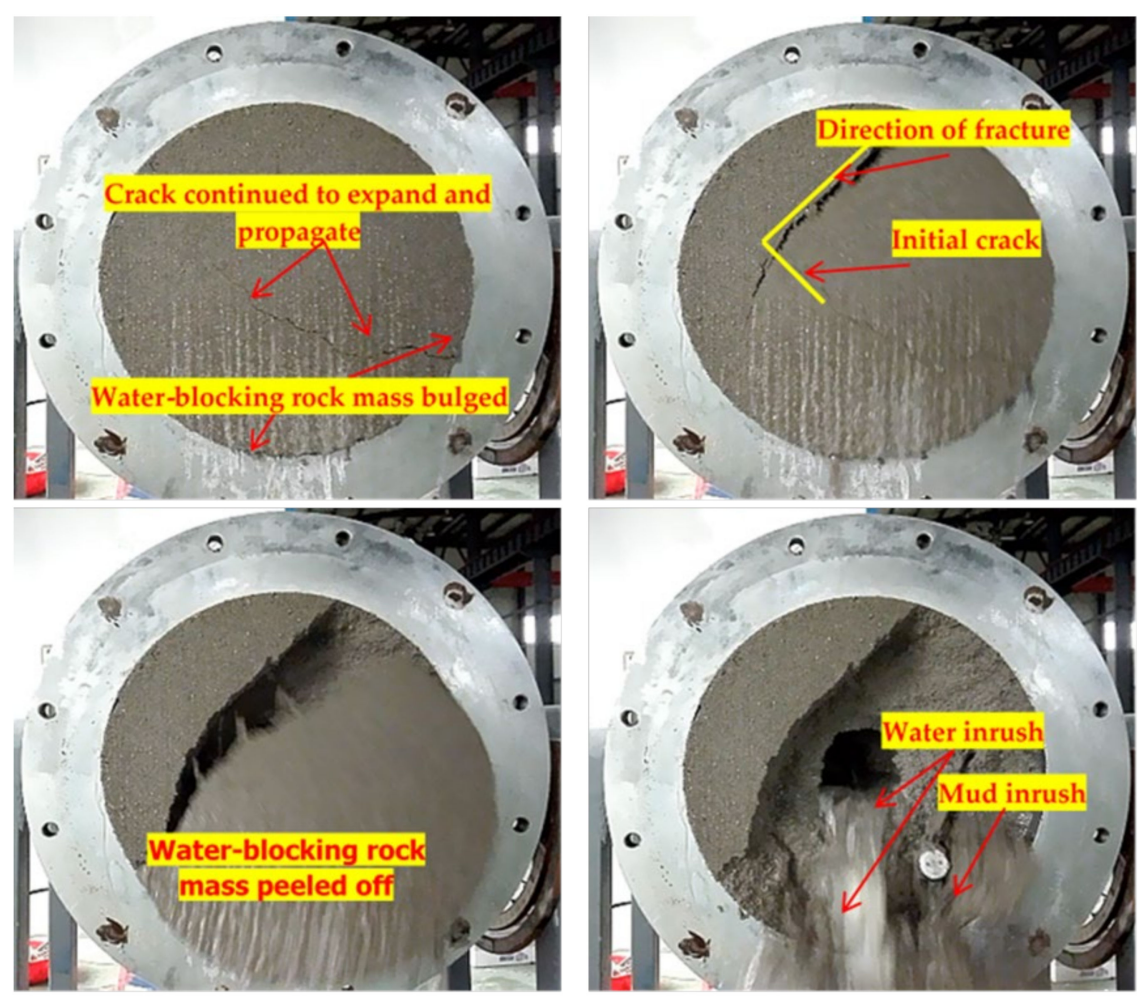

Figure 2. Test process and phenomena of water inrush 3. development of test system.

\section{Engineering Project Overview}

The Shangjiawan Tunnel is located in a deep and long tunnel in the Xiangyang section of the Baokang-Yichang Expressway in Hubei Province. The stake numbers from the beginning to the end are K64 292 to $K 68+157$, spanning a length of $3865 \mathrm{~m}$, and the maximum burial depth is $485.2 \mathrm{~m}$. The rock composition of the tunnel is mainly limestone. There are fissures and surface water catchment areas, and some sections are karst. The tunnel area has many karst depressions and is an extra-long and high-risk karst tunnel.

The left line of the Shangjiawan Tunnel was drilled at ZK64 + 918 on 31 May 2013 using the advance drilling method. During the drilling process, there was a sudden surge of strands of water, and the water inflow was approximately $200 \mathrm{~m}^{3} / \mathrm{h}$. In the excavation on June 4, there was water and mud inrush on the lower right part of the face. The instantaneous water and mud inrush reached $7700 \mathrm{~m}^{3}$, and $50 \mathrm{~cm}$ of muddy water of $50 \mathrm{~cm}$ 
poured out from the hole. The site condition is shown in Figure 3. Through exploration, it was discovered that a karst cave along the right-side wall was the source of the water inrush. The karst cave is a large filling-type cave with a length of $11 \mathrm{~m}$, a width of $10 \mathrm{~m}$ and a height of $9 \mathrm{~m}$. The plane diagram of the cave development is shown in Figure 4.

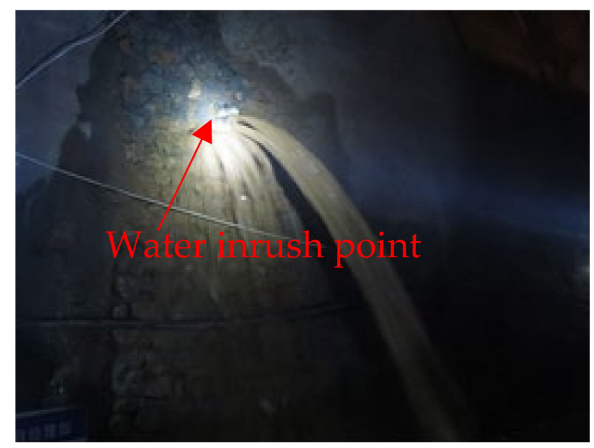

(a)

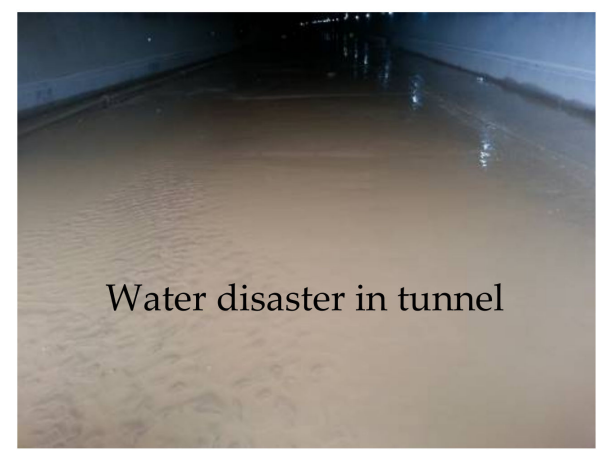

(b)

Figure 3. Site condition of water inrush in the Shangjiawan tunnel (a) water inrush point; (b) water disaster in tunnel.

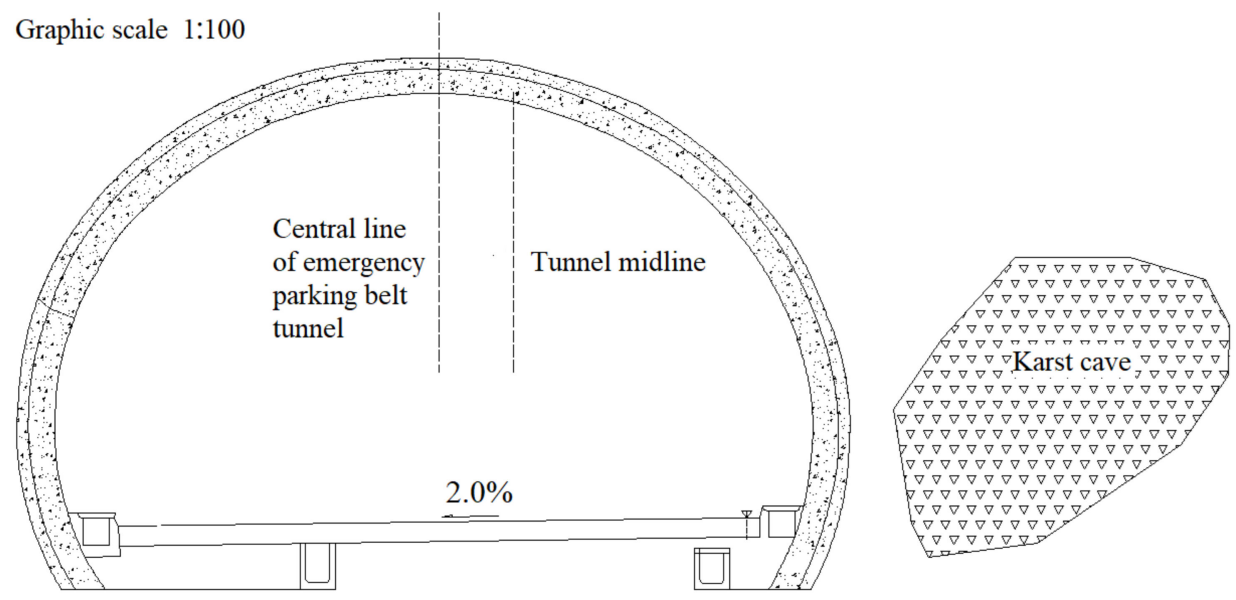

Figure 4. The left line of the Shangjiawan Tunnel exposes the development of a karst cave.

\section{Calculation Model and Parameters}

\subsection{Calculation Model}

According to the actual structural form and geological conditions of the tunnel, the ZK64 + 890 to ZK64 + 950 segments of the left line of the Shangjiawan Tunnel, with an average burial depth of $280 \mathrm{~m}$ and a groundwater level of $58 \mathrm{~m}$, are selected as the simulation range. The ANSYS software was used to establish a three-dimensional model of the tunnel that contained a water-filled karst cave, and the model was imported into FLAC3D to simulate the excavation and to develop an equilibrium solution. The $x$-axis of the model is the horizontal direction, and the range of the model along the $\mathrm{x}$-direction is from $-40 \mathrm{~m}$ to $50 \mathrm{~m}$. The $y$-axis is the vertical direction, and the range of the model along the $y$-direction is from $-40 \mathrm{~m}$ to $40 \mathrm{~m}$. The $z$-axis is the longitudinal direction, and the range of the model along the $\mathrm{z}$-direction is from $0 \mathrm{~m}$ to $-60 \mathrm{~m}$. The karst cave is simplified as a sphere with a radius of $R=5 \mathrm{~m}$ and a spherical coordinate of $(x, y, z=13 \mathrm{~m}, 0 \mathrm{~m}$, $-30 \mathrm{~m})$. The calculation model is shown in Figure 5. 


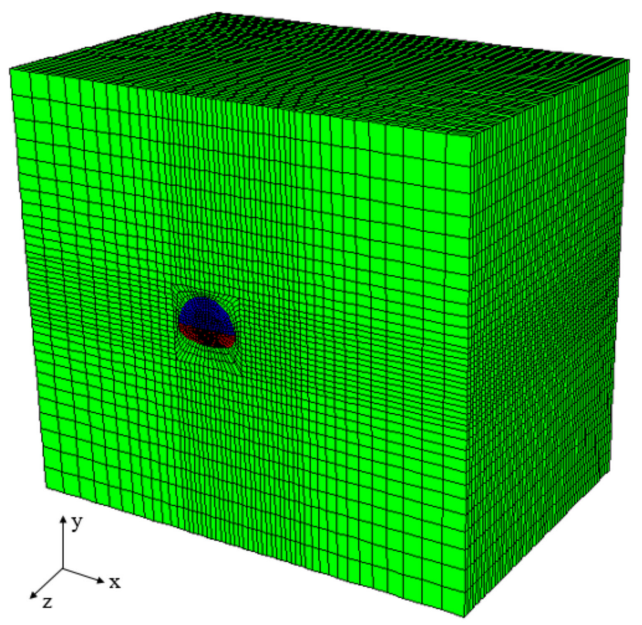

(a)

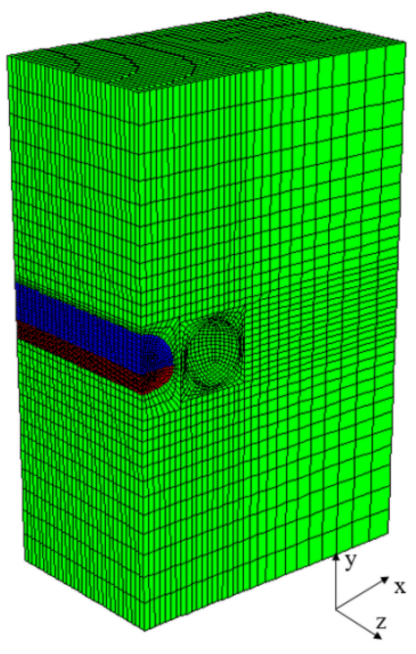

(b)

Figure 5. Model meshing: (a) front view, (b) model section.

The model calculation parameters are taken from the ZK64 + 890 to ZK64 + 950 segments of the left line of the Shangjiawan Tunnel. The rock samples of the field test section are extracted to test the series of physical and mechanical parameters of density, elastic modulus, Poisson's ratio, cohesion, internal friction angle and tensile strength of the rock mass and to measure the permeability coefficient and porosity characteristics of the rock mass. The specific parameters of the model are shown in Table 1.

Table 1. Computation parameters of the surrounding rock of the simulated tunnel section.

\begin{tabular}{cccc}
\hline Parameter & Value & Parameter & Value \\
\hline Density kg/m $/ \mathrm{m}^{3}$ & 2600 & Internal friction angle ${ }^{\circ}$ & 40 \\
Elastic modulus $/ \mathrm{Pa}$ & $6 \times 10^{9}$ & Tensile strength $/ \mathrm{Pa}$ & $1.5 \times 10^{-6}$ \\
Poisson's ratio & 0.25 & Permeability coefficient cm $/ \mathrm{s}$ & $5.2 \times 10^{-6}$ \\
Cohesion $/ \mathrm{Pa}$ & $1.2 \times 10^{12}$ & Porosity $/ \%$ & 40 \\
\hline
\end{tabular}

\subsection{Calculation and Excavation}

Horizontal displacement constraints are applied to the left and right boundaries of the model, axial displacement constraints are applied to the front and rear boundaries, and vertical displacement constraints are applied to the lower boundary. The ideal elastoplastic model and the Mohr-Coulomb yield criterion are used, and the rock mass particles are set to be incompressible (i.e., the Biot coefficient is one). The seepage calculation uses an isotropic seepage model and the steady seepage flow analysis method. At the same time, the upper surface of the model is the stress boundary of the applied load, and the lateral and bottom surfaces are normally restrained. During the excavation process, the tunnel wall and face are free boundaries. In terms of the seepage boundary, the upper surface of the model is set to be a water-permeable boundary, and the other surfaces are set to be impervious to water. The pore water pressure of the fixed tunnel wall and face is zero during the excavation process.

In the actual construction of the Shangjiawan Tunnel, the upper and lower steps were used for excavation, and the lower step lagged the upper step by three excavation cycles. Considering the influence of excavation disturbance and pace in the seepage failure zone of the karst cave, the excavation footage was $1 \mathrm{~m}$ for each cycle of the 8th to 36th excavation cycles in the actual simulation and $2 \mathrm{~m}$ for each cycle of the other excavation cycles. The excavation simulation scheme is shown in Table 2, and the specific excavation schematic is shown in Figure 6. 


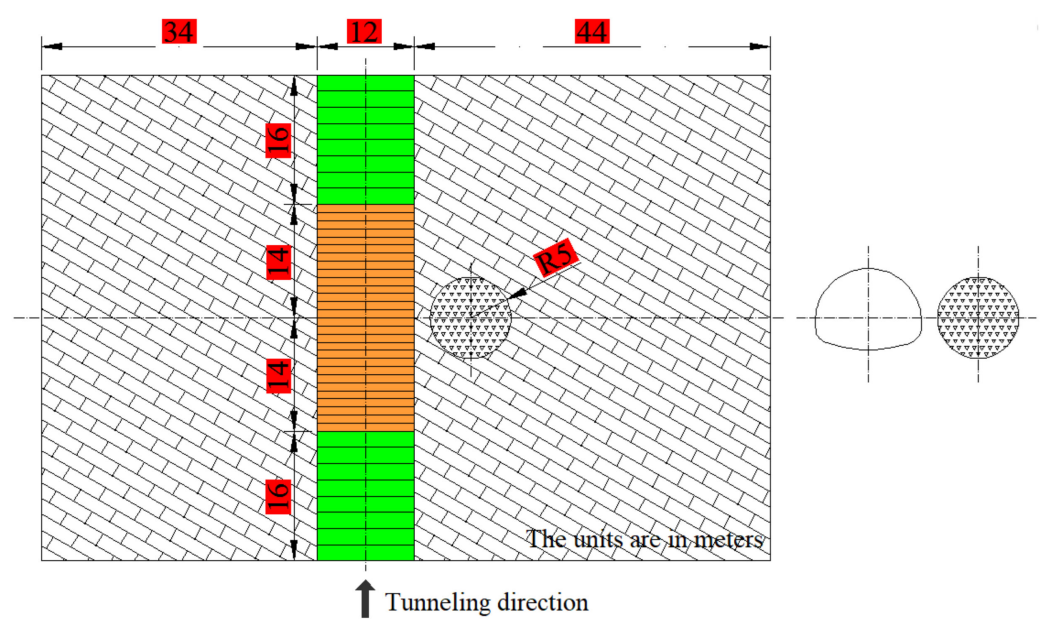

Figure 6. Schematic diagram of tunnel excavation.

Table 2. Excavation simulation plan.

\begin{tabular}{ccc}
\hline Simulation Process & Calculation Step & Calculation Content \\
\hline Initial condition & 0 & $\begin{array}{c}\text { Initial geostress balance under burial depth and water } \\
\text { pressure conditions }\end{array}$ \\
Excavation in front of the karst cave & 1 to 3 & $\begin{array}{c}\text { Excavation of the upper step, 2-m footage for each cycle } \\
\text { Lower step lagged 3 cycles, 2-m footage for each cycle } \\
\text { Step excavation, 2-m footage for each cycle }\end{array}$ \\
\hline Excavation behind the karst cave & 8 to 8 & Step excavation, 2-m footage for each cycle \\
& 22 to 36 & Step excavation, 2-m footage for each cycle \\
\hline
\end{tabular}

\section{Evolution Pattern of the Precursor Information of Water Inrush}

During the tunnel excavation process, there are three stages of the advancement of the face in front of, going through, and behind the karst cave-affected region. Multiple types of physical information, such as the stress field, the displacement field and the seepage field of the karst cave-affected region and the surrounding rock of the tunnel, are constantly changing. The method proposed by Lei [17] of setting a number of monitoring points in the plastic penetration zone of the surrounding rock to monitor the pore water pressure after the penetration of the plastic zone was used. With the advancement of the face, when the pore water pressures at the monitoring points collectively showed a steep drop, water inrush occurred.

In this paper, the change of pore water pressures in the plastic zone and at the key points is used as the criterion for water inrush, as shown in Figure 7. Through calculation, penetration of the plastic zone occurred (as shown in Figure 8) in the 20th step $(Z=-28)$. Five monitoring points (shown in Figure 9) located in the surrounding rock between the tunnel and the cave in the plastic zone were selected, and the pore water pressures at the monitoring points were extracted.

From the pore water pressure curve and the plot of the change rate of the pore water pressure at each monitoring point in Figure 10, it can be obtained that the pore water pressure reached the maximum at each monitoring point in the 11th excavation step $(Z=-19)$. Then, the pore water pressure began to decrease and reached the minimum at each monitoring point at the 25th excavation step $(Z=-33)$. According to the judgment criterion, it is determined that water inrush occurred at the 25th excavation step $(Z=-33)$. Based on this, this paper focuses on the evolution patterns of the stress field, the displacement field and the seepage field in the 11th to 25th excavation cycles. 


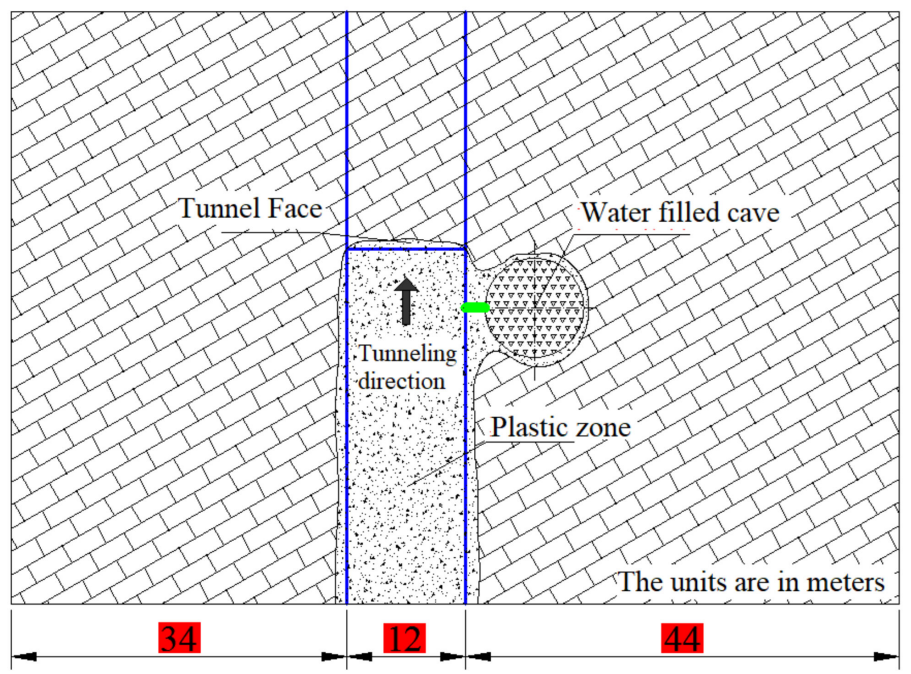

Figure 7. Schematic diagram of the surrounding rock of the tunnel and the penetration of the plastic zone.

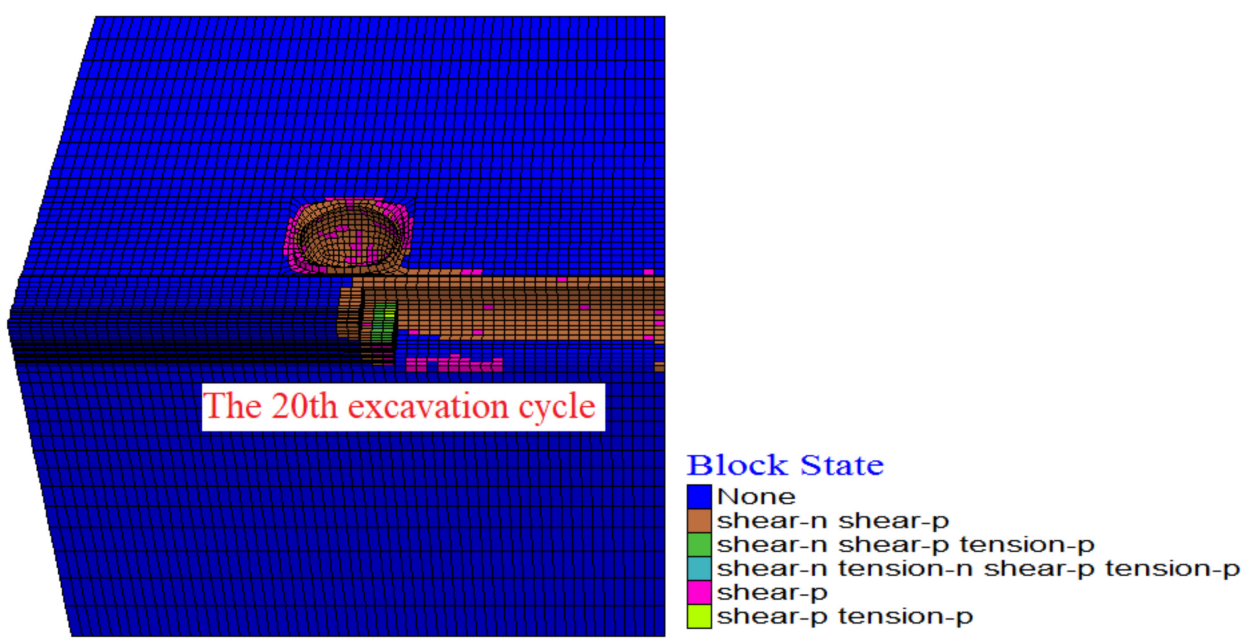

Figure 8. Tunnel surrounding rock and penetration of the plastic zone of the tunnel.

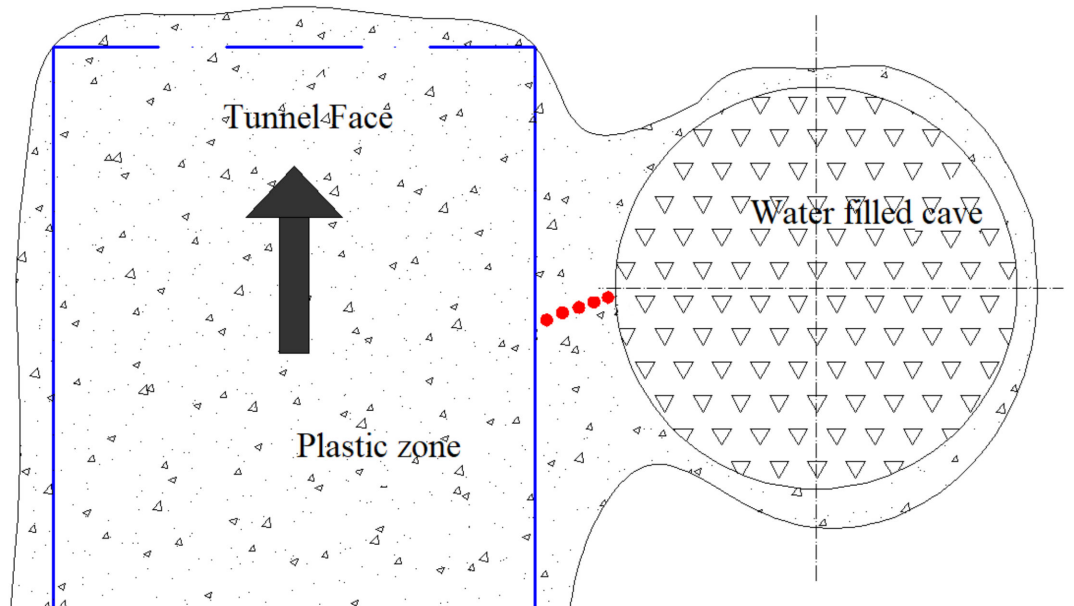

Figure 9. Layout of the monitoring points. 


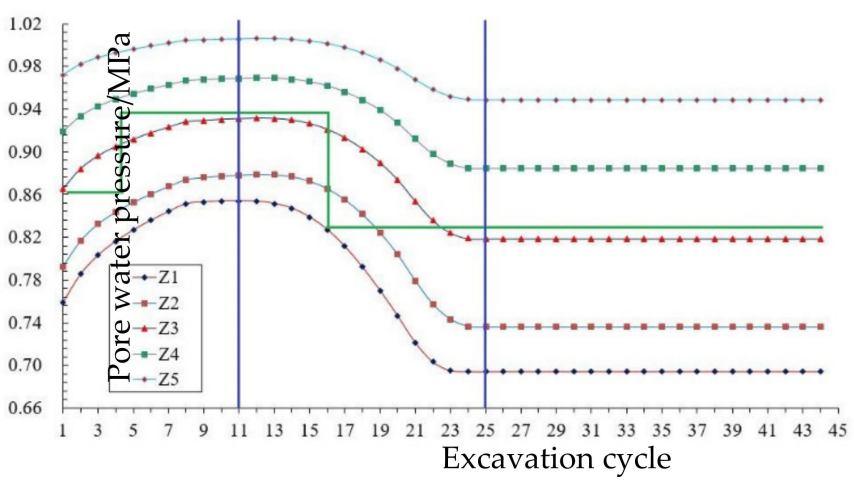

(a)

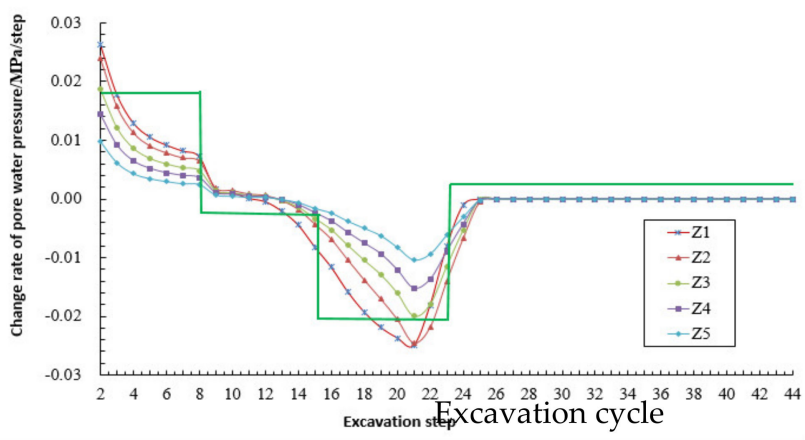

(b)

Figure 10. Pore water pressure curve and plot of the change rate of the pore water pressure at each monitoring point in the tunnel and the karst plastic zone with the advancement of excavation. (a) Pore water pressure at different excavation cycles for each monitoring point; (b) Change rate of the pore water pressure at each monitoring point.

\section{Data Fusion Analysis of Precursor Information}

\subsection{Normalization of Data}

A large amount of information, such as the displacement, stress, and seepage pressure, is extracted from the test. For the comprehensive analysis of the trend of each physical quantity and their mutual influence pattern, it is necessary to map these data to the same coordinate system. Normalizing the test data will meet this requirement well. Normalization is used to map data to a range of 0 to 1 , which is a way to simplify calculations. After the formula is transformed, the dimensional expression is transformed into a dimensionless expression. In the conversion to a linear function, if the range of the sample data is set as [min, $\max ]$, then the normalized expression is:

$$
y_{i}=\mathrm{g}(\mathrm{x})=\frac{x_{i}-\min \left(x_{i}\right)}{\max \left(x_{i}\right)-\min \left(x_{i}\right)}
$$

This is a linear function with the following properties: if the size relationship of the sample remains is unchanged, i.e., $x_{1}<x_{2}$, then $\mathrm{g}\left(x_{1}\right)<\mathrm{g}\left(x_{2}\right)$; if the relative distance of the sample remains the same, i.e., $d_{1}=\left|x_{1}-x_{2}\right|, d_{2}=\left|x_{3}-x_{4}\right|, d_{1}^{\prime}=\left|\mathrm{g}\left(x_{1}\right)-\mathrm{g}\left(x_{2}\right)\right|$, and $d_{2}^{\prime}=\left|\mathrm{g}\left(x_{3}\right)-\mathrm{g}\left(x_{4}\right)\right|$, then $d_{1}: d_{2}=d_{1}^{\prime}: d_{2}^{\prime}$. 


\subsection{Multivariate Information Mutation Analysis}

Figure 11a shows the time history of the maximum principal stress at monitoring point 1-1 of monitoring section III, Figure $11 \mathrm{~b}$ shows the time history of the minimum principal stress at monitoring point 1-1 of monitoring section III, Figure 11c shows the time history of the displacement in the $\mathrm{Y}$ direction, Figure 11d is the time history of the seepage pressure, and Figure 11e shows the normalization curves of the linear functions of the information of the three fields. Monitoring point 1-1 at monitoring section III was at the vault. It can be obtained from Figure $11 \mathrm{a}, \mathrm{b}$ that the maximum and minimum principal stresses of the monitoring point underwent a change from compressive stress to tensile stress. The maximum and minimum principal stress fluctuated during the 21st excavation step, and during the 22nd excavation step the compressive stress was converted into tensile stress. The stress was also converted into tensile stress in the 21st excavation step before water inrush occurred. It can be seen from Figure 11c that the vertical displacement of monitoring point 1-1 was at a lower value before the start of excavation and increased slowly, and the rate of displacement growth increased at the 19th excavation step. After the occurrence of water inrush, the growth rate slowed down. It can be seen from Figure 11d that the seepage pressure at the monitoring point reached a high value soon after the tunnel was excavated. As the face advanced toward the monitoring point, the seepage pressure value decreased, the reduction rate of the seepage pressure decreased before the occurrence of water inrush, and the seepage pressure dropped to the lowest value when water inrush occurred. From the normalized curve of the linear function in Figure 11e, the information of the three fields at monitoring point 1-1 can be obtained. The first change is the displacement field, followed by the change of the stress field, and finally the change of the seepage pressure field.

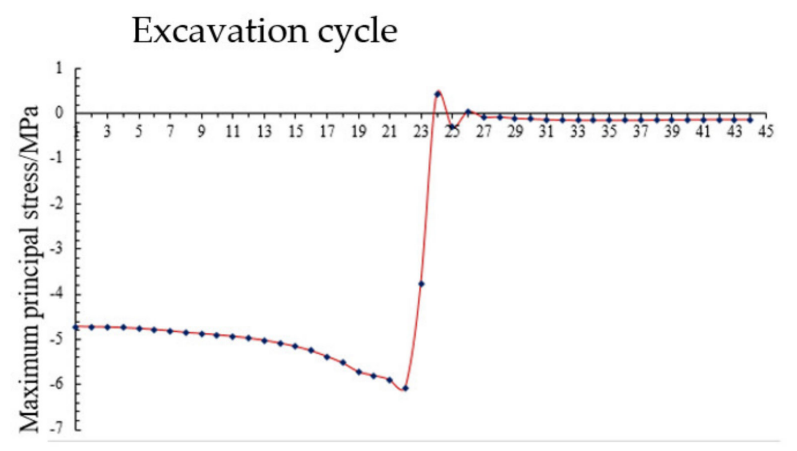

(a)

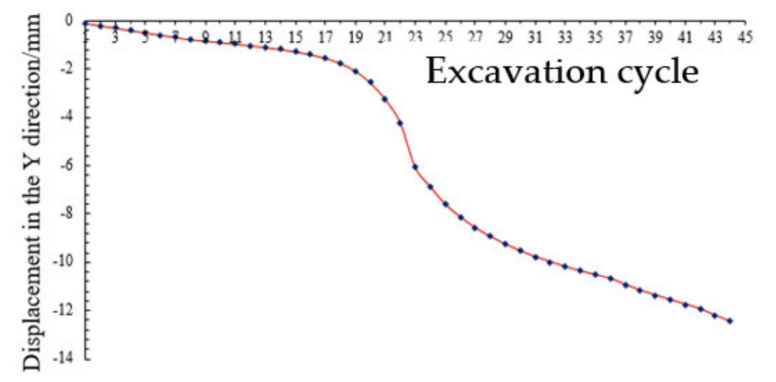

(c)

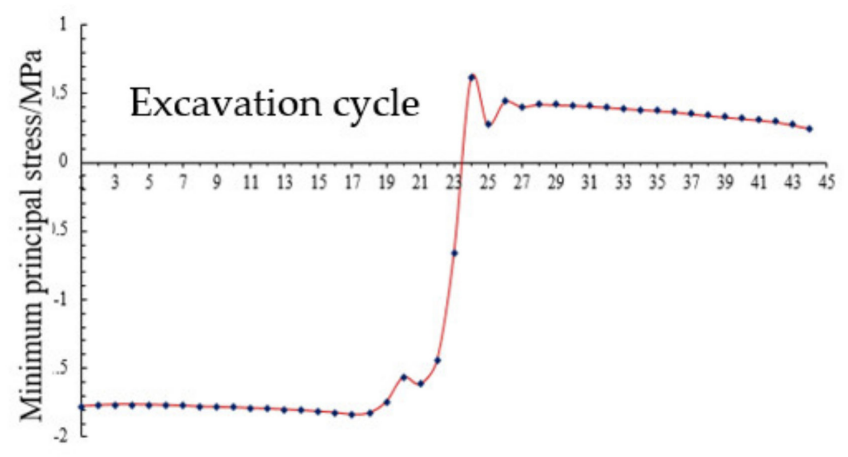

(b)

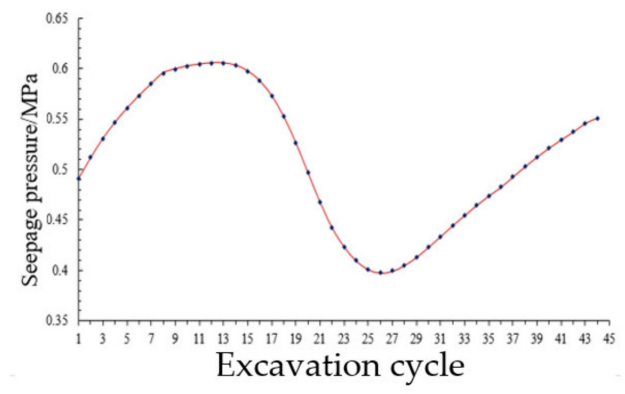

(d)

Figure 11. Cont. 


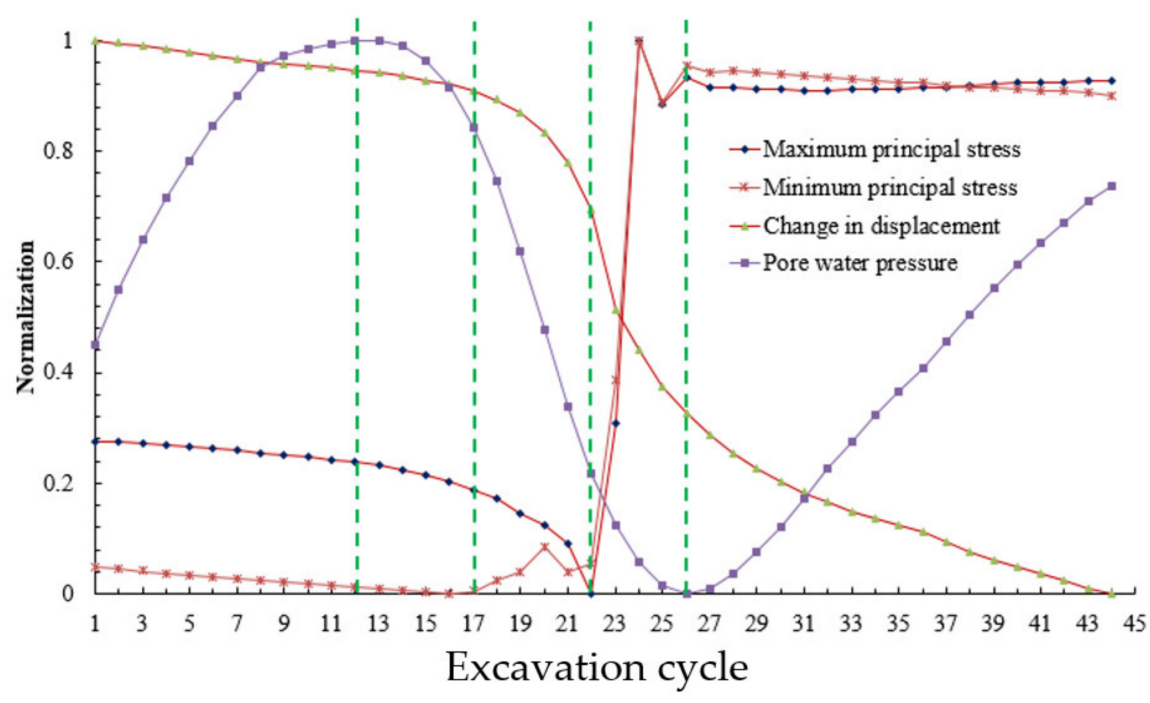

(e)

Figure 11. Variation curves of multivariate information at monitoring point 1-1 of monitoring section III. (a) Time history of maximum principal stress; (b) Time history of minimum principal stress; (c) Time history of displacement in the Y direction; (d) Time history of seepage pressure; (e) Normalization curves of linear functions.

Figure 12a shows the time history of the maximum principal stress at monitoring point R-1, Figure $12 \mathrm{~b}$ is the time history of the minimum principal stress, Figure $12 \mathrm{c}$ is the time history of displacement in the $\mathrm{x}$ direction, Figure $12 \mathrm{~d}$ is the time history of the seepage pressure, and Figure 12e shows the normalization curves of the linear functions of the information of the three fields. Monitoring point R-1 was at the vault.

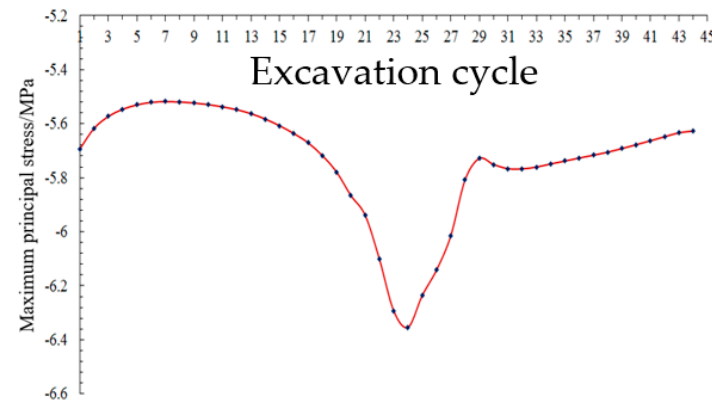

(a)

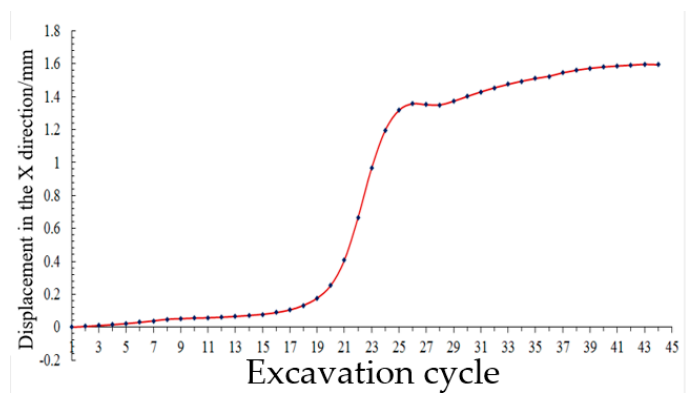

(c)

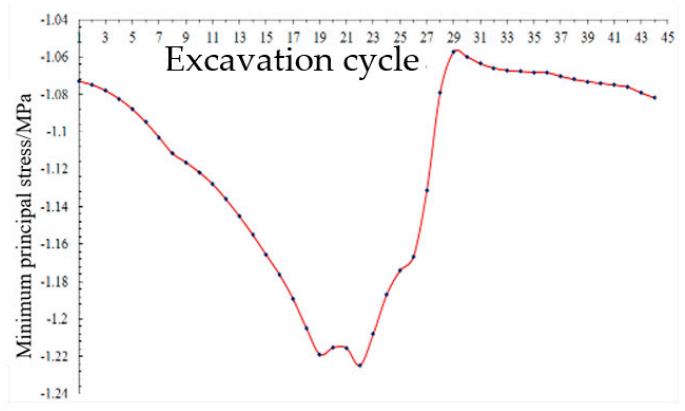

(b)

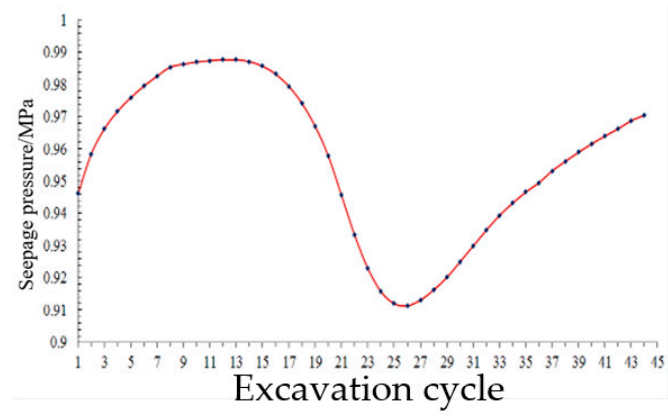

(d)

Figure 12. Cont. 


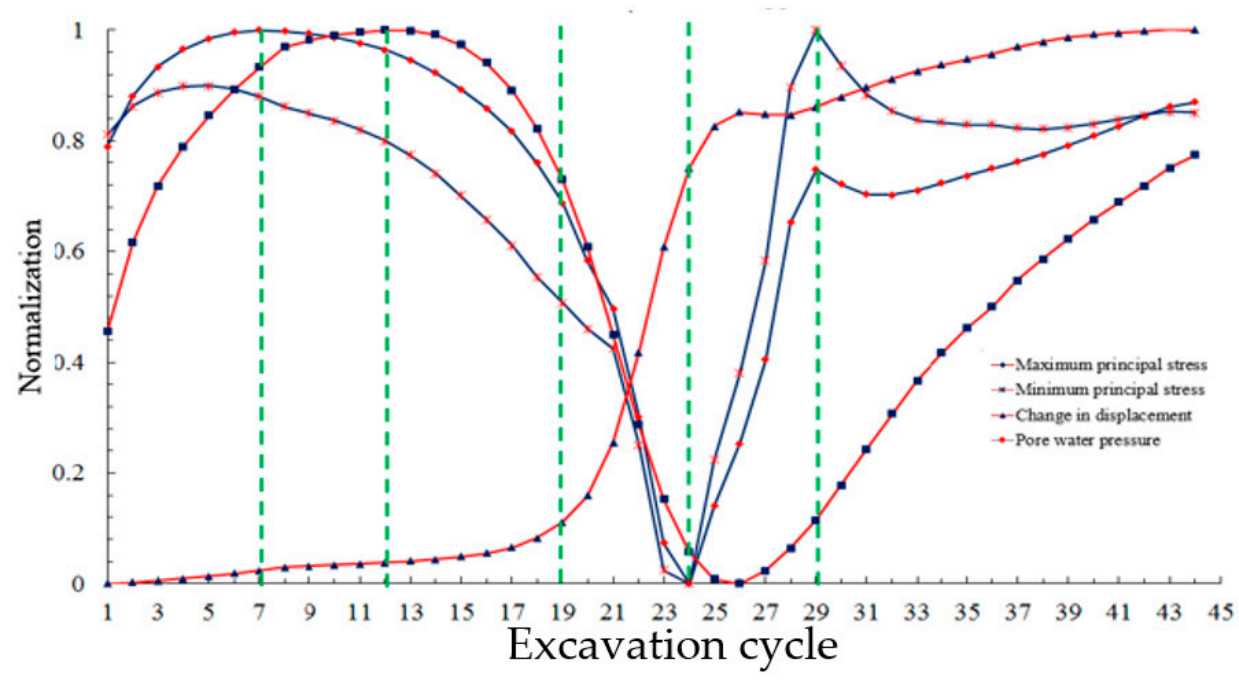

(e)

Figure 12. Variation curves of multivariate information at monitoring point R-1. (a) Time history of maximum principal stress; (b) Time history of minimum principal stress; (c) Time history of displacement in the x direction; (d) Time history of seepage pressure;(e) Normalization curves of linear functions.

It can be seen from Figure 12a,b that the maximum and minimum principal stresses of monitoring point R-1 were both expressed as compressive stresses. The maximum and minimum principal stresses before water inrush sharply increased, reaching the maximum at the occurrence of water inrush. After the water inrush, the principal stress decreased rapidly due to the release of stress. As seen from Figure 12c, the horizontal displacement of monitoring point 1-1 was at a lower value before the start of excavation and grew slowly. At the 17th excavation step, the rate of displacement growth accelerated, and the rapid growth trend was stagnant when water inrush occurred. The rate of growth slowed down after the occurrence of water inrush. It can be seen from Figure 12d that the seepage pressure at the monitoring point was similar to that at monitoring point 1-1 of monitoring section III. After tunnel excavation, the seepage pressure rapidly reached a high value. As the face advanced toward the monitoring point, the seepage pressure decreased, and the reduction rate of the seepage pressure slowed down before water inrush occurred. The seepage pressure dropped to the lowest value when water inrush occurred. From the normalized curves of the linear functions in Figure 12e, the information of the three fields at monitoring point R-1 can be obtained. The stress field changed first, followed by the displacement field changed and then the seepage pressure field.

Figure 13a is the time history of the maximum principal stress at monitoring point Z-1, Figure $13 \mathrm{~b}$ is the time history of the minimum principal stress, Figure $13 \mathrm{c}$ is the time history of the displacement in the $\mathrm{X}$ direction, Figure 13d is the time history of the seepage pressure, and Figure 13e is the normalization curves of the linear functions of the information of the three fields. Monitoring point Z-1 was the monitoring point on the left arch of the tunnel. At the 17th excavation step, the face passed through the section where the monitoring point was located. It can be seen from Figure 13a,b that the maximum and minimum principal stresses of monitoring point Z-1 are both expressed as compressive stresses. The maximum principal stress was maintained at approximately $5.3 \mathrm{MPa}$ in the initial stage of excavation. Before the excavation of the face to the 17th excavation step, the maximum principal stress increased greatly and reached its maximum when the face passed through the section where Z-1 was located. Then, the maximum principal stress dropped steeply, reaching a low value of approximately 3.2 MPa before water inrush occurred. As seen from Figure 13c, the horizontal displacement of monitoring point Z-1 was at a lower value before the start of excavation and grew slowly. The displacement was positive before the face was pushed to the section where monitoring point Z-1 was located. After the face 
passed through, the displacement became negative, that is, the tunnel was restrained, and the displacement increased rapidly before water inrush occurred. It can be seen from Figure $13 \mathrm{~d}$ that the seepage pressure of the monitoring point reached a high value soon after the tunnel excavation. As the face advanced toward monitoring point Z-1, the seepage pressure decreased, and the reduction rate of the seepage pressure before water inrush showed a slowing trend. The seepage pressure decreased to a minimum when water inrush occurred. It can be obtained from the normalized curves of the linear functions in Figure 13e that the stress field changed first, followed by the displacement field and then the seepage field.

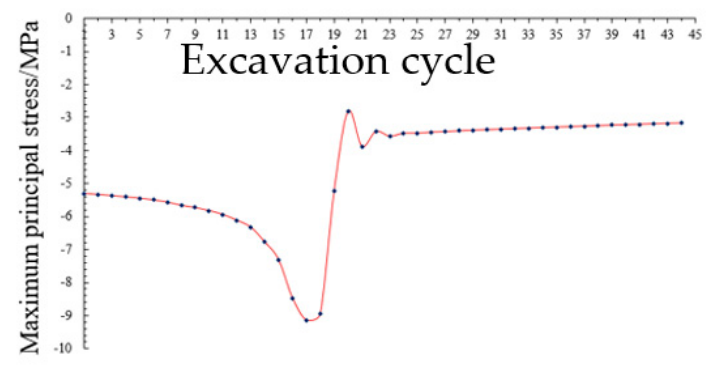

(a)

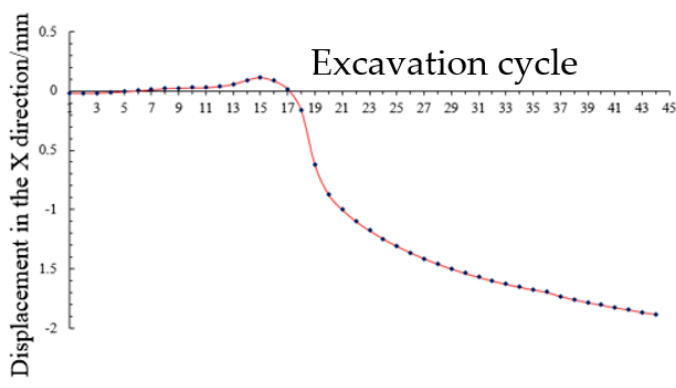

(c)

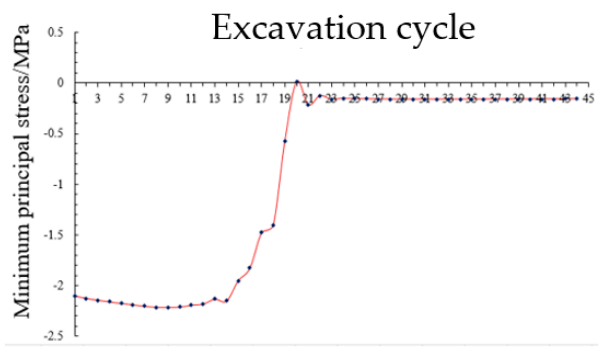

(b)

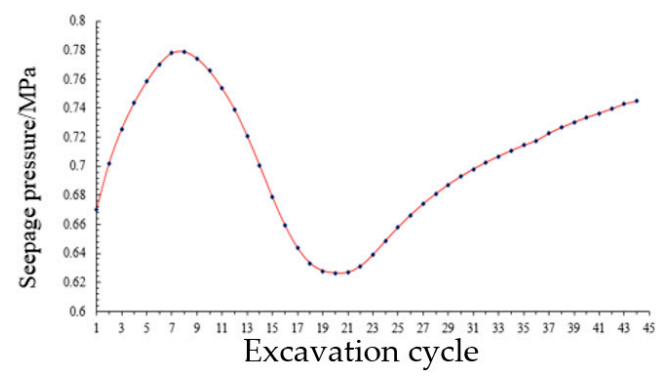

(d)

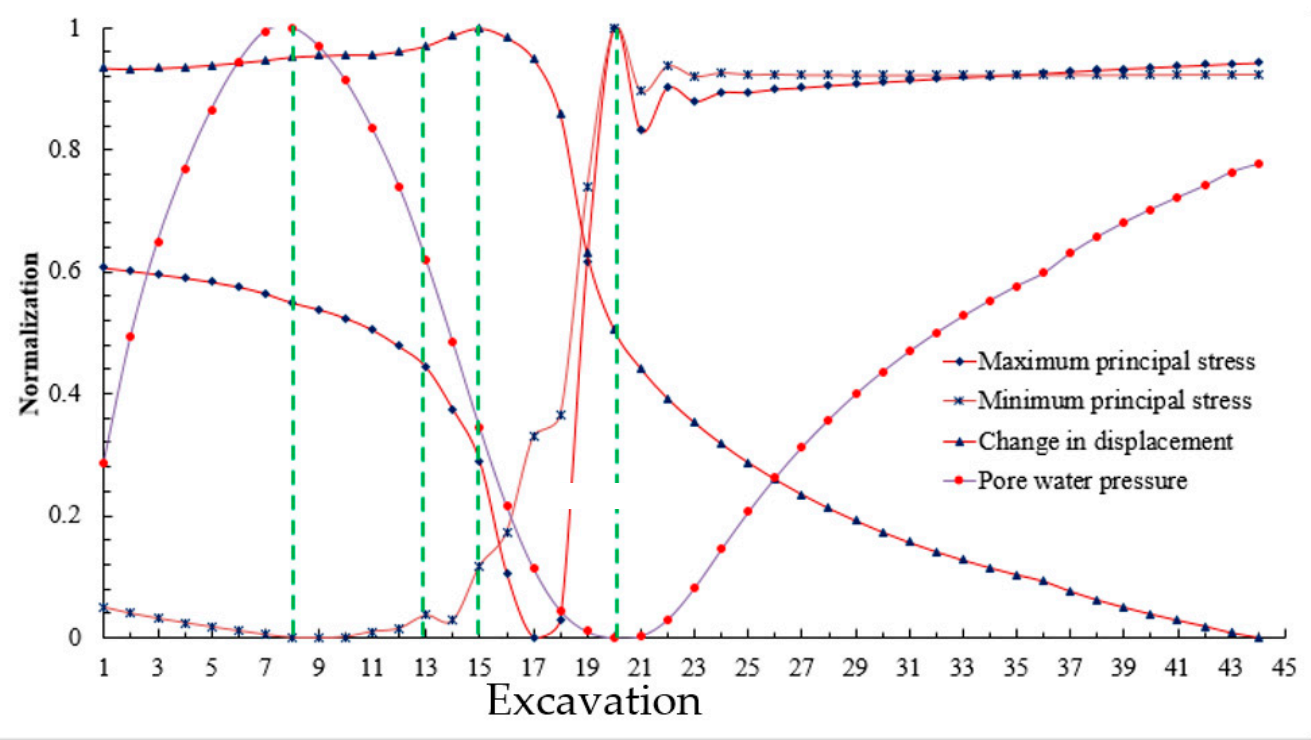

(e)

Figure 13. Variation curves of multivariate information at the monitoring point Z-1. (a) Time history of maximum principal stress; (b) Time history of minimum principal stress; (c) Time history of displacement in the x direction; (d) Time history of seepage pressure; (e) Normalization curves of linear functions. 


\subsection{Matching Mode of the Precursor Information of Water Inrush}

In the above three-dimensional numerical simulations of the special case in which the karst cave is located at the horizontal position of the lateral side of the tunnel, the evolution patterns of the multifield precursor information of the stress field, the displacement field and the seepage field are obtained. The normalization processing method of linear functions is used to normalize the data to realize the mutation analysis of the water inrush precursor information. It can be obtained from the data extracted by the numerical simulation that the occurrence sequence of the multifield characteristic information of the precursor of the monitoring point located at the tunnel arch of the cave side is as follows: stressfield $\rightarrow$ displacement-field $\rightarrow$ seepage-field.

The matching mode of the precursor information of water inrush shows that the stress field increases first and then decreases, the displacement field increases constantly, and the seepage field increases first and then decreases. Specifically, the stress field first increases and then decreases as the face progresses toward the disaster source because the excavation disturbance and the water pressure of the disaster source cause a concentration of stress in the surrounding rock. Then, with the advancement of the face, the distance between the stress concentration point and the free face decreases, and the stress decreases rapidly with the unloading effect of excavation. The displacement shows a growth trend from the beginning, and the rate of stress growth rapidly increases when the face is excavated close to the disaster source. The evolution pattern of the seepage field is similar to that of the stress field, and it also increases first and then decreases. The matching mode of the characteristic information of the precursors of the multiple fields is shown in Table 3.

Table 3. Matching mode of the characteristic information of the precursors of the multiple fields.

\begin{tabular}{ccccc}
\hline Information of Each Field & Stress Field & Displacement Field & Seepage Field & Microseismic Information \\
\hline Response pattern & $\uparrow \downarrow$ & $\uparrow$ & $\uparrow \downarrow$ & $\uparrow$ \\
\hline
\end{tabular}

\section{Discussion}

In this paper, the specific model of a spherical karst cave located on one side of the tunnel is mainly used for calculation, which has certain limitations in the summary of laws. Therefore, there is a lack of universality in the analysis of evolution and fusion of precursory information of water inrush caused by fracture of a water-resisting rock mass structure. In addition, the range of physical and mechanical parameters and boundary conditions used in numerical calculation is limited, which is also not comprehensive. The results show that the relationship between water inrush and various internal and external factors can be revealed, and the matching mode of water inrush precursor information can be more complete.

\section{Conclusions}

(1) Relying on the case of water inrush in the Shangjiawan Tunnel of the BaokangYichang Expressway in Hubei Province, the finite element software Ansys was used to establish the calculation model of the karst cave. The cave was simplified into a sphere, and the model was imported into the finite difference software FLAC3D to simulate excavation and to find an equilibrium solution.

(2) Through the normalization of the data, a catastrophe analysis of the multivariate information is carried out. The matching mode of the precursor information of water inrush after the fracture of the water-blocking rock is proposed.

(3) The occurrence sequence of the characteristic information of the precursors of the multiple fields of water inrush after the fracture of the water-blocking rock is in the following order: stress-field $\rightarrow$ displacement-field $\rightarrow$ seepage-field. The matching mode of the precursor information of water inrush shows that the stress field increases first and then decreases, the displacement field increases constantly, and the seepage field increases first and then decreases. 
Author Contributions: J.S. and J.W. conceived and designed the experiments; D.C. performed the experiments; Y.B. and S.L. analyzed the data; G.Z. contributed reagents/materials/analysis tools; D.C. and C.W. wrote the paper; J.W. and C.W. constructed the manuscript structure in the manuscript revision. All authors have read and agreed to the published version of the manuscript.

Funding: This research was funded by National Natural Science Foundation of China (Grant No. 51809157, 51809158, 51709160, 51909143), Shandong Provincial Natural Science Foundation, China (Grant No. ZR2019BEE024, ZR2018BEE045), China Postdoctoral Science Foundation (2018M630780), Shandong Transportation Science and Technology projects (Grant No. 2018B58).

Institutional Review Board Statement: Not applicable.

Informed Consent Statement: Not applicable.

Data Availability Statement: No new data were created or analyzed in this study. Data sharing is not applicable to this article.

Conflicts of Interest: The authors declare no conflict of interest.

\section{References}

1. Li, X.; Li, Y. Research on risk assessment system for water inrush in the karst tunnel construction based on GIS: Case study on the diversion tunnel groups of the Jinping II Hydropower Station. Tunn. Undergr. Space Technol. 2014, 40, 182-191. [CrossRef]

2. Chu, H.; Xu, G.; Yasufuku, N.; Yu, Z.; Liu, P.; Wang, J. Risk assessment of water inrush in karst tunnels based on two-class fuzzy comprehensive evaluation method. Arab. J. Geosci. 2017, 10, 179. [CrossRef]

3. Qian, Q. Challenges faced by underground projects construction safety and countermeasures. Chin. J. Rock Mech. Eng. 2012, 31, 1945-1956.

4. Markauskas, D.; Kruggel-Emden, H.; Sivanesapillai, R.; Steeb, H. Comparative study on mesh-based and meshless coupled CFD-DEM methods to model particle-laden flow. Powder Technol. 2016, 305, 78-88. [CrossRef]

5. Xue, Y.; Wang, D.; Li, S.; Qiu, D.; Li, Z.; Zhu, J. A risk prediction method for water or mud inrush from water-bearing faults in subsea tunnel based on cusp catastrophe model. KSCE J. Civ. Eng. 2017, 21, 2607-2614. [CrossRef]

6. Akinci, N.; Ihmsen, M.; Akinci, G.; Solenthaler, B.; Teschner, M. Versatile rigid-fluid coupling for incompressible SPH. ACM Trans. Graph. 2012, 31, 1-8. [CrossRef]

7. Robinson, M.; Ramaioli, M.; Luding, S. Fluid—particle flow simulations using two-way-coupled mesoscale SPH—DEM and validation. Int. J. Multiph. Flow 2014, 59, 121-134. [CrossRef]

8. Li, S.C.; Liu, H.L.; Li, L.P.; Zhang, Q.Q.; Wang, K.; Wang, K. Large scale three-dimensional seepage analysis model test and numerical simula-tion research on undersea tunnel. Appl. Ocean Res. 2016, 59, 510-520. [CrossRef]

9. Alija, S.; Torrijo, F.J.; Quinta-Ferreira, M. Geological engineering problems associated with tunnel construction in karst rock masses: The case of Gavarres tunnel (Spain). Eng. Geol. 2013, 157, 103-111. [CrossRef]

10. Li, S.; Tian, H.; Xue, Y.; Su, M.; Qiu, D.; Li, L.; Li, Z. Study on Major Construction Disasters and Controlling Technology at the Qingdao Kiaochow Bay Subsea Tunnel. J. Coast. Res. 2015, 73, 403-409. [CrossRef]

11. Zarei, H.R. Identifying geological hazards related to tunneling in carbonate karstic rocks-Zagros, Iran. Arab. J. Geosci. 2012, 5, 457-464. [CrossRef]

12. Zhang, G.H.; Jiao, Y.Y.; Ma, C.X.; Wang, H.; Chen, L.B.; Tang, Z.C. Alteration characteristics of granite contact zone and treatment measures for inrush hazards during tunnel construction-A case study. Eng. Geol. 2018, 235, 64-80. [CrossRef]

13. Li, L.; Tu, W.; Shi, S.; Chen, J.; Zhang, Y. Mechanism of water inrush in tunnel construction in karst area. Geomat. Nat. Hazards Risk 2016, 7, 35-46. [CrossRef]

14. Odintsev, V.N.; Miletenko, N.A. Water inrush in mines as a consequence of spontaneous hydrofracture. J. Min. Sci. 2015, 51, 423-434. [CrossRef]

15. Hou, X.; Shi, W.; Yang, T. A non-linear flow model for the flow behavior of water inrush induced by the karst collapse column. RSC Adv. 2018, 8, 1656-1665. [CrossRef]

16. Ma, D.; Miao, X.; Bai, H.; Huang, J.; Pu, H.; Wu, Y.; Zhang, G.; Li, J. Effect of mining on shear sidewall groundwater inrush hazard caused by seepage instability of the penetrated karst collapse pillar. Nat. Hazards 2016, 82, 73-93. [CrossRef]

17. Yang, W.M.; Wang, H.; Yang, X.; Zhang, B.; Yang, L.; Fang, Z.D.; Wang, M.X. Development and application of model test system for water inrush in high-geostress and high hydraulic pressure tunnels. Chin. J. Rock Mech. Eng. 2017, 36, 992-994. 